\title{
Copper Like Thermal Conductivity and Silicon Like Coefficient of Thermal Expansion Copper Graphene for High Power IGBT by Metal Injection Molding
}

\author{
Farhad Mohammadi ${ }^{1}$ and Sheng-Shian $\mathrm{Li}^{1,2, *}$ \\ ${ }^{1}$ Institute of NanoEngineering and MicroSystems, National Tsing Hua University, Hsinchu, Taiwan \\ ${ }^{2}$ Department of Power Mechanical Engineering, National Tsing Hua University, Hsinchu, Taiwan
}

Enhanced stability, lifetime and safety of high power IGBT (Insulated Gate Bipolar Transistor) modules are a result of their progressive material selection, thereby necessitating the invention of new composite materials. High-end power modules are operated close to the maximum physical matching capability of their layered materials, leading to decreased lifetime and degraded performance, and thus creating demand for new composite materials with higher thermal conductivity and lower coefficient of thermal expansion (CTE). To eliminate failures caused by the CTE mismatch $(\sim 300 \%)$ between metal and substrate material interface, we report for the first time $\mathrm{Cu} / \mathrm{Gr}-\mathrm{Cu}$ composite which exhibits similar thermal conductivity to pure copper $(390 \mathrm{~W} /(\mathrm{m} \cdot \mathrm{K}))$, much higher than the range of metal injection molded copper heat sink (320$340 \mathrm{~W} /(\mathrm{m} \cdot \mathrm{K}))$, while featuring low silicon-like CTE $(\sim 5 \mathrm{ppm} / \mathrm{K})$. This is realized by injection parameter manipulation to not only reduce voids (vacancies) but increase the interface bonding through the use of electrodeposited copper on graphene (i.e., Gr-Cu). Such excellent property locates the $\mathrm{Cu} / \mathrm{Gr}-\mathrm{Cu}$ in the top of the Ashby map and shows excellent temperature stability with lower thermal distortion parameter (TDP). Thus, this excellent composite material is the only material simultaneously with high thermal conductivity and low CTE, making it uniquely suited for high power module applications, especially for hybrid and electric vehicles. [doi:10.2320/matertrans.M2018136]

(Received April 24, 2018; Accepted August 8, 2018; Published October 25, 2018)

Keywords: coefficient of thermal expansion, copper powders, graphene, metal injection molding, thermal conductivity, insulated-gate bipolar transistor

\section{Introduction}

The IGBT modules play an important role in high power applications, such as hybrid and electric vehicles inverters. In such applications, the IGBT devices are working under heavy thermal cycling stresses; therefore, the reliability of these devices is continuously improved to meet current stringent demand. However, the complex structure mismatch of multilayer materials, such as different coefficient of thermal expansion in each layer, causes severe thermo-mechanical fatigue failure and power loss. ${ }^{1,2}$ As illustrated in Fig. 1, (a) shows the back side view of an IGBT power module while (b) presents its schematic indicating the complete device assembly with its various layers, such as the chip, DCB substrate (direct copper bonding substrate) and pin-fin heat sink, respectively.

Even though the silicon integrated circuits (IC) have been invented for more than fifty years and now become mainstream in semiconductor industry due to their costeffectiveness, silicon still exhibits several critical limitations considering its ability of voltage blocking, working temperature and switching frequency. Therefore, alternative materials based on wide bandgap (WBG) semiconductors, such as $\mathrm{SiC}, \mathrm{GaN}, \mathrm{Al}_{2} \mathrm{O}_{3}, \mathrm{AlN}$ and etc., with much higher conduction and switching properties than silicon can be the suitable candidate for IGBT power modules materials. These devices (e.g., chip in Fig. 1(b) ${ }^{3)}$ ) will tolerate higher voltages and temperature than silicon-based devices. With all of these features, wide bandgap IGBT modules materials position themselves in emerging applications. Nevertheless, the WBG materials are costly for manufacturing and production as compared to silicon. ${ }^{4,5)}$

*Corresponding author, E-mail: ssli@mx.nthu.edu.tw

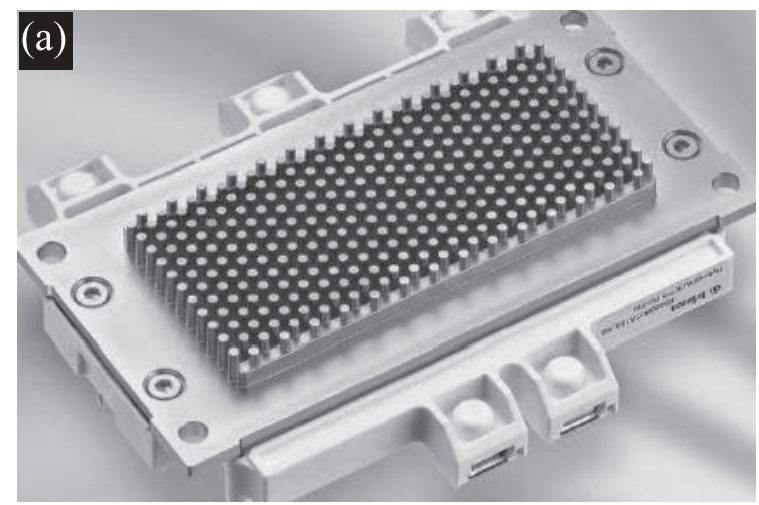

(b)

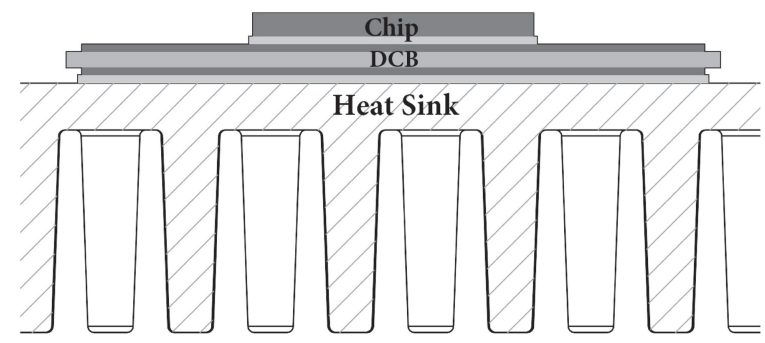

Fig. 1 (a) IGBT power module assembly with the pin-fin heat sink. ${ }^{38)}$ (b) IGBT power module schematic illustrating the chip, DCB substrate, and pin-fin heat sink. ${ }^{3)}$

Most of the IGBT modules consist of WBG transistors required for high power operation with considerable heat dissipation. Due to significant temperature rise during the operation of IGBT, issues of delamination, buckling and uneven distribution of strain occur due to CTE mismatch among different layers of the IGBT modules so they would 
further degrade heat removal efficiency. ${ }^{6)}$ As a result, it is necessary to choose as similar CTE and thermal conductivity as possible for materials used in IGBT. ${ }^{7}$ In addition to the search of materials with similar CTE for IGBT, a potential solution to address the heat generation issue is to increase the overall thermal conductivity of the substrates, including DCB and heat sink, used in IGBT for minimizing temperature rise. Since the excellent thermal conductivity of graphene has been reported, ${ }^{8,9)}$ in this work we considered to use graphene into copper to enhance the thermal property of the composite for a pin-fin heat sink in IGBT modules. From literature, ${ }^{10,11)}$ a mixture of metal and graphene has been extensively investigated. Even with an excellent thermal conductivity of graphene, the addition of graphene into copper always developed the phase segregation among the composite, thus leading to overall lower thermal conductivity. ${ }^{12)}$ Furthermore, a combination of nano-carbons and copper to achieve low CTE also becomes very challenging. ${ }^{13)}$

In this work, we developed $\mathrm{Cu} / \mathrm{Graphene}-\mathrm{Cu}(\mathrm{Cu} / \mathrm{Gr}-\mathrm{Cu})$ composite through a metal injection molding process where copper coated graphene $(\mathrm{Gr}-\mathrm{Cu})$ is mixed into the copper baseplate to form required IGBT heat sink with a metal like thermal conductivity such as pure metal injected copper of $320-340 \mathrm{~W} /(\mathrm{m} \cdot \mathrm{K})$. Also, the proposed composite material features low CTE $(5.48 \mathrm{ppm} / \mathrm{K})$ similar to silicon, revealing the potential integration with silicon-based circuits, which not only offers cost-effective solutions but also adds more value into system implementation. To attain such material properties, we developed a unique copper coated graphene $(\mathrm{Gr}-\mathrm{Cu})$ and metal injection molding process to realize high thermal conductivity and low CTE simultaneously. Finally, we achieved the best $\mathrm{Cu} / \mathrm{Gr}-\mathrm{Cu}$ composite property mixture as it is illustrated in Ashby map. Furthermore, it exhibits the low thermal distortion parameter (TDP) as expected, which makes this composite to be the best choice among all other materials for power electronics and modules. The definition of essential abbreviations used throughout this paper is provided as follows to avoid any confusion.

- $\mathrm{Cu} / \mathrm{Gr}:$ Copper feedstock, which graphene (Gr) is added to it.

- Gr-Cu: Graphene, which is coated (electro-deposited) by thin-layer copper.

- $\mathrm{Cu} / \mathrm{Gr}-\mathrm{Cu}$ : Copper feedstock, which is mixed with copper coated graphene.

- $\mathrm{Cu} / 0.2 \% \mathrm{Gr}-\mathrm{Cu}$ : Copper feedstock, which is mixed with $0.2 \%$ copper coated graphene.

- $\mathrm{Cu} / 0.4 \% \mathrm{Gr}-\mathrm{Cu}$ : Copper feedstock, which is mixed with $0.4 \%$ copper coated graphene.

- $\mathrm{Cu} / 0.6 \% \mathrm{Gr}-\mathrm{Cu}$ : Copper feedstock, which is mixed with $0.6 \%$ copper coated graphene.

- Ashby plot is a scatter plot which displays two or more properties of materials. ${ }^{14)}$

- TDP is indicating the temperature induced deformation of electronic packaging materials. ${ }^{15)}$

- Standard Volume: Copper metal standard index for each measurement property.

- Copper-like: The measured result is almost similar to copper.

- Silicon-like: The measured result is almost similar to silicon.

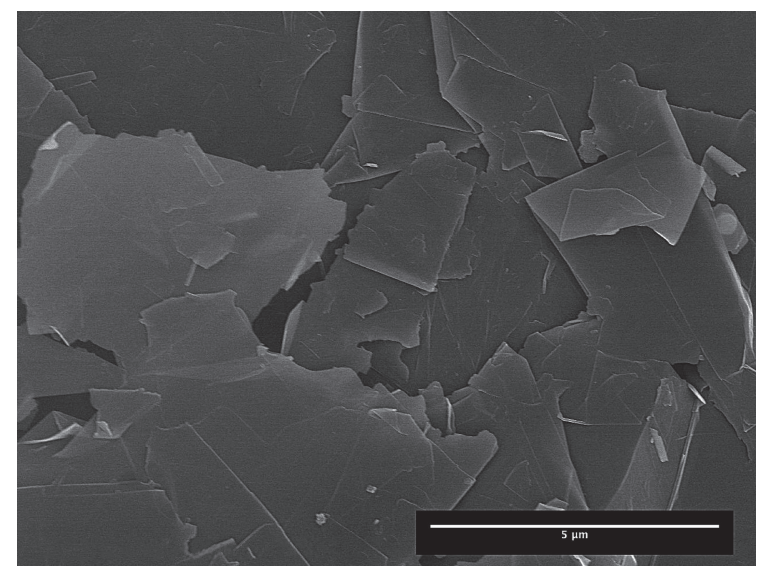

Fig. 2 Electrodeposited copper-coated graphene $(\mathrm{Gr}-\mathrm{Cu})$.

- DCB: Direct copper bonding substrate, also known as DBC.

- The CNT density is volume density.

\section{Material Preparation and Experiment Materials}

First, Donated Multi-layer graphene powder (Gr) (PML20, thickness: $\sim 5 \mathrm{~nm}$, surface area: $\left.\sim 25 \mathrm{~m}^{2} / \mathrm{g}\right),{ }^{16)}$ was coated by a thin copper layer through an electrodeposition method for further characterization. ${ }^{10,17)}$ Graphene sheets were functional group prepared already to avoid any agglomeration. Some other surfactants, such as sodium dodecyl sulfate (SDS), were added to the solution, plus $\mathrm{H}_{2} \mathrm{SO}_{4}$ for solution conductivity, while $\mathrm{H}_{2} \mathrm{SO}_{4}$ was also used to maintain $\mathrm{pH}$ value as the $\mathrm{pH}$ would rise during the reaction. The electrolyte $\mathrm{Cu}$ concentration was set to $0.65 \mathrm{gm} / \mathrm{L}$ with the copper bar as anode and titanium as a cathode. The electrodeposition was then carried out, thus resulting in copper thin film layer of $2-3 \mathrm{~nm}$ thickness on graphene as shown in Fig. 2.

In general, the electrodeposition process is fairly straightforward and cost-effective methods to homogeneously compound filler materials with nanoscale dimensions. Also, due to the low-temperature electrodeposition process, it also maintains the graphene properties. The copper coated graphene materials were prepared by pulse reverse electrodeposition (PRED). ${ }^{10,18,19)}$ There are several advantages of electrodeposition methods; for example, metal-nanocarbons can be formed at ambient temperature and atmospheric pressure. ${ }^{17,20)}$ The homogenous dispersion is the most critical part of metal-nanocarbon matrix preparation. ${ }^{19,21,22)}$

The other metallic and polymeric resources used for the feedstock, such as copper powders (JB-201502), wax, polypropylene (PP), and polystyrene (PS), were arranged and used without additional adjustment.

\section{Feedstock Preparation}

Wax-polymer binders are widely used to be blended into the copper powders thanks to their matching property and tendency to the copper powders. Considering this tendency, various binder plans were considered in this work as a worthy alternative to be applied to each experimental recipe to 
Table 1 Feedstock recipe.

\begin{tabular}{lll}
$\mathrm{Cu}+0.2 \% \mathrm{Gr}$ & $\mathrm{Cu}+0.4 \% \mathrm{Gr}$ & $\mathrm{Cu}+0.6 \% \mathrm{Gr}$ \\
\hline $\mathrm{Cu}=85.0 \%$ & $\mathrm{Cu}=84.8 \%$ & $\mathrm{Cu}=84.6 \%$ \\
$\mathrm{Gr}=0.2 \%$ & $\mathrm{Gr}=0.4 \%$ & $\mathrm{Gr}=0.6 \%$ \\
$\mathrm{Wax}=7.95 \%$ & $\mathrm{Wax}=7.95 \%$ & $\mathrm{Wax}=7.95 \%$ \\
$\mathrm{PP}=3.74 \%$ & $\mathrm{PP}=3.74 \%$ & $\mathrm{PP}=3.74 \%$ \\
$\mathrm{PS}=3.11 \%$ & $\mathrm{PS}=3.11 \%$ & $\mathrm{PS}=3.11 \%$
\end{tabular}

achieve the required results. In metal injection molding of copper feedstock, the adequate amount of solid loading depends on the particular powder morphology and packing aspects. Thus, it usually varies depending on copper powder selection. Typical solid loading, wax and polymeric binders with graphene are shown in Table 1 vol\% for water-atomized processed powders. To disperse the copper coated graphene into the molten binders (wax, PP, and PS), the advance ultrasonic mixer 16000 (Hielscher) $^{23)}$ was used for 5 minutes. Eventually, the copper powders were added to the mixture of wax, binders, and copper coated graphene; then materials were mixed for 25 minutes at $220^{\circ} \mathrm{C}$ through laboratory Kneader as shown in Fig. 3.

\section{Molding}

The copper feedstock molding is relatively straightforward although filling up the thin wall parts are challenging due to the high thermal conductivity of the copper feedstock. That is because when the part thickness is very thin, the injected feedstock cools down much faster as it will transfer the heat to the mold in a higher rate, therefore bringing various issues during injection, such as defects. Essentially, the cross contamination should be avoided during whole feedstock preparation process; otherwise, several defects will show up in the final part, and it will affect thermal conductivity. ${ }^{24)}$ The injection molding was carried out as shown in Fig. 3 with two different injection parameters as indicated in Table 2. Different parameter sets lead to different material properties, which will be discussed later.

\section{Debinding and Sintering}

As illustrated in Fig. 3, the final parts can be debinded using solvent and thermal methods. In our experiment, the solvent debinding was done at $60^{\circ} \mathrm{C}$ for 8 hours. To reduce the harmful factors which may affect densification, the environment atmosphere should be carefully controlled. The thermal debinding of the wax-based metal injected components in the air might result in cracking, while debinding under argon gas may cause slumping. Next, thermal debinding was done within nitrogen gas at $475^{\circ} \mathrm{C}$ for 2 hours and sintering at $1040^{\circ} \mathrm{C}$ for 5 hours in a long sintering furnace, and then in the following 2 hours, the component was under cooling process. In order to eliminate further issues associated with water vapor, the oxygen amount in the sintering environment should be decreased. ${ }^{24,25)}$ Elimination

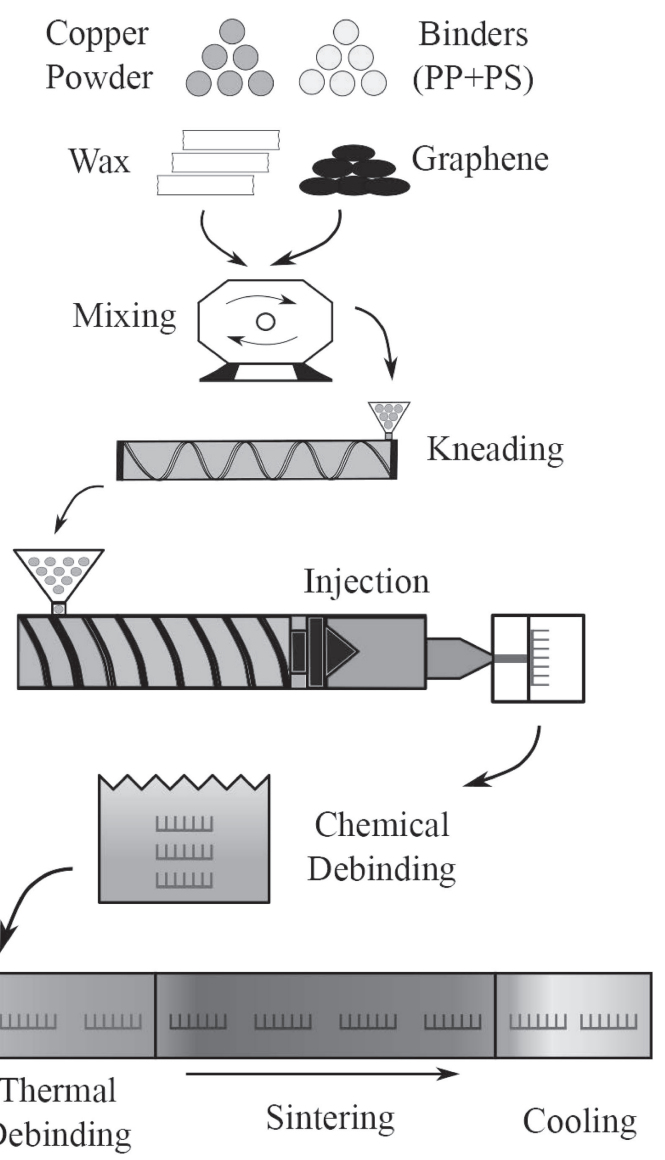

Fig. 3 Metal injection molding (MIM) process. The first step, feedstock preparation was carried out through mixing the copper powders, binders, wax, and graphene, followed by kneading to achieve the higher melt flow index (MFI), which is necessary for flowability of feedstock during injection and filling out the whole heatsink die. Next, chemical debinding in $60^{\circ} \mathrm{C}$ came after injection to take out the wax from the part, but the binders still kept the powders attached to each other and maintained the part's structure until reaching the sintering furnace. The last stage was (i) thermal debinding in $475^{\circ} \mathrm{C}$, in which all binders were vaporized, (ii) subsequent sintering in $1040^{\circ} \mathrm{C}$ to form the part by combining the copper powders, and (iii) finally cooling the part.

Table 2 Injection parameters.

\begin{tabular}{lccc} 
& $\begin{array}{c}\text { Pressure } \\
\left(\mathrm{kg} / \mathrm{cm}^{2}\right)\end{array}$ & $\begin{array}{c}\text { Feedstock } \\
\text { Temp. }\left({ }^{\circ} \mathrm{C}\right)\end{array}$ & $\begin{array}{c}\text { Time } \\
(\mathrm{s})\end{array}$ \\
\cline { 2 - 4 } Exp.1(Cu/Gr) & 550 & 220 & 155 \\
Exp.2 $(\mathrm{Cu} / \mathrm{Gr}-\mathrm{Cu})$ & 550 & 220 & 155
\end{tabular}

of oxygen in the sintering would enhance pore closing that leads to near up to $92 \%$ density of the final part. Therefore, it usually needs nitrogen sintering along with properly planned thermal cycles. ${ }^{26,27)}$

\section{Thermal Conductivity, Specific Heat, Electrical Conductivity and CTE Measurement}

The thermal measurement evaluation was carried out using the LFA 447 Nano flash (Netzsch). ${ }^{28)}$ In this method, the face side of a plane-parallel sample is heated by a small light pulse. The resulting temperature increase on the back surface 


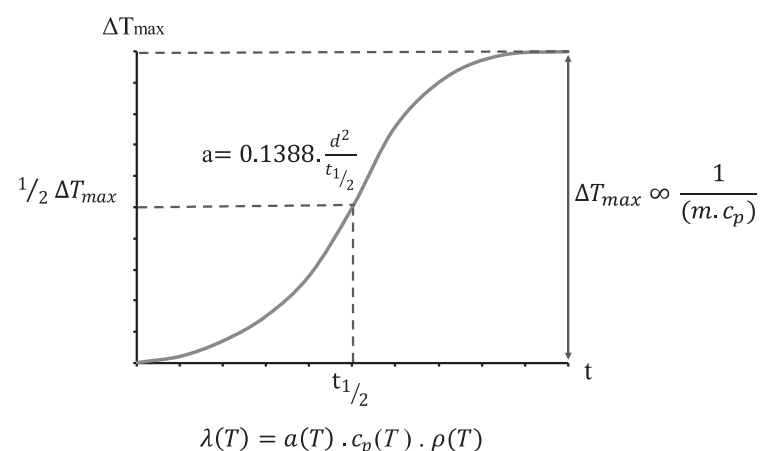

Fig. 4 Temperature vs. Time graph. Using the halftime $\left(\mathrm{t}_{1 / 2}\right.$, time value at half signal height) and sample thickness (d), the thermal diffusivity (a) and finally, the thermal conductivity $(\lambda)$ can be calculated using the formula in Fig. 2. Furthermore, the specific heat $\left(c_{p}\right)$ of solids can be determined using the signal height $\left(\Delta T_{\max }\right)$ compared to the signal height of reference material.

is measured using an infrared detector. By examining the resulting temperature versus time curve, the thermal diffusivity can be determined. Through measuring thermal diffusivity $(a)$ of a copper metal composite, its thermal conductivity $(\lambda)$ can be determined if specific heat $\left(c_{p}\right)$ and density $(\rho)$ are known. All the related measurements will be done by advanced data analysis through the half-time method $\left(t_{1 / 2}\right.$, time value at half signal height) as shown in the following equation:

$$
a=0.1388 \cdot \frac{d^{2}}{t_{\frac{1}{2}}}
$$

where $a$ is thermal diffusivity, $d$ is sample thickness, and $t$ is time.

This similarly permits the consideration of radial, facial heat losses, and finite pulse effects by advanced mathematical regression routines. Using the metaproperty measurement capabilities, both thermal diffusivity and specific heat can be determined simultaneously, therefore, yielding thermal conductivity if the density is known using the eq. (2) and Fig. 4:28)

$$
\lambda(T)=a(T) \cdot c_{p} \cdot \rho(T)
$$

where $\lambda$ is thermal conductivity, $c_{p}$ is specific heat, $T$ is temperature, and $\rho$ is density.

During the sample's thermal conductivity measurement, the experimental specific heat $\left(c_{p}\right)$ is obtained as a series of complementary data.

The SIGMASCOPE SMP10 (Helmut-Fischer $\mathrm{GmbH})^{29}$ ) was used to measure the electrical conductivity of produced samples that is an eddy current technique built on DIN EN 2004-1 and ASTM E 1004. The mentioned equipment provides contact-free determination of the electrical conductivity through a phase sensitive measurement signal assessment. The measurement frequency causes the penetration depth of the eddy currents, which defines the least permitted thickness of the sample. Due to the user-friendly menu of equipment's software, the operator can easily select the device settings for the measurement use, perform evaluations, and present the measurement outcomes in the preferred method, i.e., not only in a numerical setup but also in a graphical setup via added specification bounds or as a histogram.

The CTE sample of each set of experiment was measured using high resolution and stable DIL 402 PC (Netzsch). ${ }^{30)}$ Interchangeable furnaces with temperature range up to $1200^{\circ} \mathrm{C}$ and $1600^{\circ} \mathrm{C}$ serve to allow for higher expansion tests on $\mathrm{Cu} / \mathrm{CNT}$ 's metal matrix mixture detail analysis. The sample is placed in the even temperature region of the furnace. The furnace is heated according to a preselected temperature plan. Through using the control thermocouple, the furnace temperature is controlled by the time. The sample is presented with a temperature-dependent difference in length. The examination temperature is measured via the sample thermocouple. So, there is measured and recorded the sum of variation in length of the sample, the test carrier, and the pushrod. The pushrod transfers this change in length mechanically to the displacement transducer (LVDT) and produces a movement of the core of the displacement transducer (LVDT). The resulting difference in voltage is transformed through a carrier frequency measuring amplifier to a DC voltage which is proportional to the displacement. Moreover, lastly, the outcoming signal is recorded by a processer. ${ }^{30)}$

\section{Results and Discussion}

Metal injection molding (MIM) combines the strength and durability of metal with the flexibility inherent in the injection molding process. MIM is a highly cost-effective method for producing a wide variety of components and is an excellent alternative to other forms of manufacturing metallic parts, such as die-casting, investment casting and many forms of machining. Typically, ideal parts for MIM are small in size and range, weight up to 500 grams. Complex geometries, tight tolerances, high density and exceptional repeatability, are some of the characteristics that make MIM the go-to process for metal parts production in a variety of industries. The SEMs (SU8200, Hitachi) ${ }^{31)}$ (cf. Fig. 5(a), (b)) shows the microstructure of the final parts after $\mathrm{Cu} / \mathrm{Gr}$ metal injection molding (Exp.1) and $\mathrm{Cu} / \mathrm{Gr}-\mathrm{Cu}$ metal injection molding with the help of electrodeposition (Exp.2), respectively. This allows us to perform a detailed analysis and observe the two individual experiments for comparison. The SEM images of copper and graphene in each figure, including $\mathrm{Cu} / \mathrm{Gr}$ and $\mathrm{Cu} / \mathrm{Gr}-\mathrm{Cu}$ feedstock, can be seen.

Achieving to the proper amount of porosity and density in the produced final part is always one of the biggest challenges in metal injection molding (MIM) process. Therefore, It has a direct effect on final physical and mechanical properties. Thus, several factors such as metal powder shape, the suitable parameters of metal injection molding, debinding and sintering processes got the huge effect on the outcomes. ${ }^{3)}$ Base on the experimental result in the Fig. 6(a), the lowest porosity occurs in Exp. 2 of $0.2 \%$ Graphene and therefore it will cause the highest density Fig. 6(b), which occurs in Exp.2 of $0.2 \%$ Graphene. Furthermore, by increasing the Graphene amount from $0.2 \%$ to $0.4 \%$ and $0.6 \%$ respectively, it results in the porosity increase and density decrease. The Graphene tendency to the agglomeration is the main reason to cause this issue. By the 

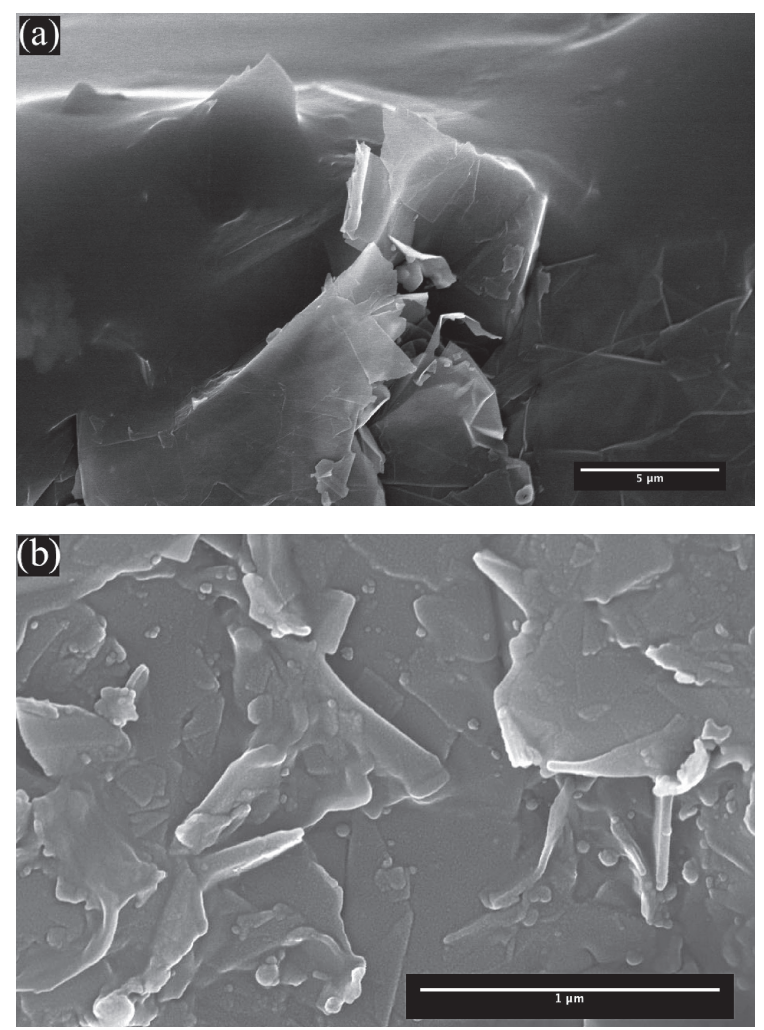

Fig. 5 (a) $\mathrm{Cu} / \mathrm{Gr}$ composite SEM image. (b) $\mathrm{Cu} / \mathrm{Gr}-\mathrm{Cu}$ composite SEM image using copper coated graphene $(\mathrm{Gr}-\mathrm{Cu})$.
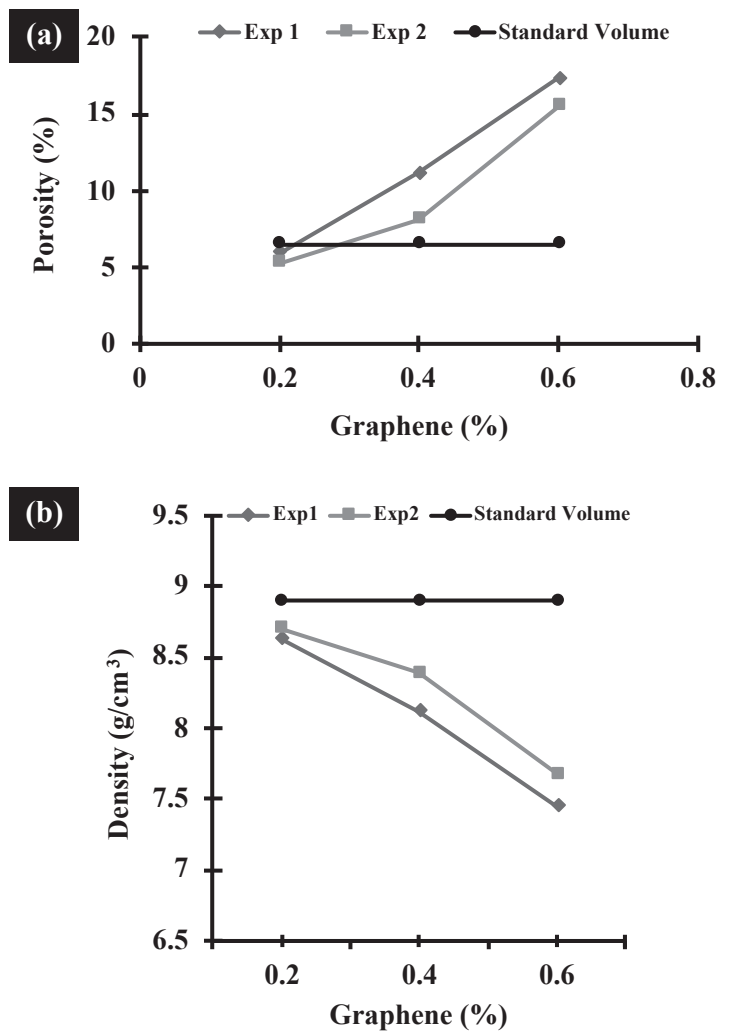

Fig. 6 (a) Lowest porosity occurs in Exp. 2 of $0.2 \%$ Graphene. (b) Highest density occurs in Exp. 2 of $0.2 \%$ Graphene.

way, by adjusting the injection parameters and using the copper-coated Graphene, the porosity amounts various from Exp. 1 to Exp. 2 and cusses the lower value of porosity and therefore higher density in the $0.2 \%$ Graphene.
Thermal conductivity range of copper metal injection molding based on porosity and impurities varies from 280 to $385 \mathrm{~W} /(\mathrm{m} \cdot \mathrm{K}){ }^{32)}$ In contrast, the thermal conductivity of commercially pure copper alloys could reach $390 \mathrm{~W} /(\mathrm{m} \cdot \mathrm{K})$ concerning metallic impurity ranges under $50 \mathrm{ppm}$ and also oxygen contents up to 0.04 mass $\%$. Commercially $100 \%$ pure cast coppers, for example, C83400, feature smaller thermal conductivities, usually near $340-350 \mathrm{~W} /(\mathrm{m} \cdot \mathrm{K})$, just as employing deoxidizers, such as silicon, tin, zinc, aluminum, and etc. ${ }^{33)}$

As illustrated in Fig. 7(a), there is great improvement in thermal conductivity from Exp.1 (280.8, 298.56 and 329.64 $\mathrm{W} /(\mathrm{m} \cdot \mathrm{K}))$ to Exp.2 $(334.38,379.38$ and $390 \mathrm{~W} /(\mathrm{m} \cdot \mathrm{K}))$ based on $0.6 \%, 0.4 \%$ to $0.2 \%$ graphene, respectively. This was done with metal injection parameter setting in Exp.2 and enhancement of the interface bonding by adding the copper coated graphene $(\mathrm{Gr}-\mathrm{Cu})$, which was made by an electroplating process. However, the injection setting and higher interface bonding of the $\mathrm{Cu} / 0.2 \% \mathrm{Gr}-\mathrm{Cu}$ composite (in comparison to MIM pure $\mathrm{Cu}$ ) results in thermal conductivity of $390 \mathrm{~W} /(\mathrm{m} \cdot \mathrm{K})$ which is being much greater than the range of $\mathrm{MIM} \mathrm{Cu}(320-340 \mathrm{~W} /(\mathrm{m} \cdot \mathrm{K}))$ and even equal to pure copper $(390 \mathrm{~W} /(\mathrm{m} \cdot \mathrm{K}))$. This composite $(390 \mathrm{~W} /(\mathrm{m} \cdot \mathrm{K}))$ represents an almost 95 times (Percentage increased) higher thermal conductivity against comparative dielectrics (with lower CTE) such as Copper Tungsten $(200 \mathrm{~W} /(\mathrm{m} \cdot \mathrm{K})$. Having addressed the thermal conductivity of the copper-graphene matrix, similarly, the electrical conductivity behaves the same. As illustrated in Fig. 7(b), based on adding the various amount of the $0.6 \%, 0.4 \%$ to $0.2 \%$ copper-coated Graphene, there is also a significant improvement in the electrical conductivity from Exp.1 to Exp.2. By achieving this result, selection of the materials will be far more convenient for various purposes, which is beyond the current conventional materials. The experimental specific heat $\left(c_{p}\right)$ of the coppergraphene metal matrix with various graphene contents are shown in Fig. 7(c). Based on that, there is increase range in specific heat from Exp.1 $(0.292,0.312$ and $0.322(\mathrm{~J} / \mathrm{g} \cdot \mathrm{K}))$ to Exp.2 $(0.325,0.353$ and $0.381(\mathrm{~J} / \mathrm{g} \cdot \mathrm{K}))$ in terms of $0.6 \%, 0.4 \%$ to $0.2 \%$ graphene, respectively. Thus, due to the efficiency of specific heat propagation, the graphene dissipation uniformity in the copper-graphene composite will contribute to the steady increase of thermal conductivity up to $390 \mathrm{~W} /(\mathrm{m} \cdot \mathrm{K})$ in Exp.2 with $0.2 \%$ graphene.

On the other hand, the coefficient of thermal expansion (CTE) is plotted as illustrated in Fig. 8, where the overall amount of CTE is much smaller than pure $\mathrm{Cu}(17 \mathrm{ppm} / \mathrm{K})$ from Exp.1 (6.2682, 5.7836 and $5.3791 \mathrm{ppm} / \mathrm{K})$ to Exp.2 $(6.4170,5.8044$ and $5.4886 \mathrm{ppm} / \mathrm{K})$ based on $0.2 \% \mathrm{Gr}$, $0.4 \% \mathrm{Gr}$ to $0.6 \% \mathrm{Gr}$, which is approaching $\mathrm{Si}$ and other IGBT substrate materials. When compared with percentage decrease between copper (Standard volume of $17 \mathrm{ppm} / \mathrm{K}$ in Fig. 8), the $\mathrm{Cu} / \mathrm{Gr}-\mathrm{Cu}$ composite $(5.4886 \mathrm{ppm} / \mathrm{K})$ exhibits an almost $68 \%$ lower CTE.

In general, the average $\mathrm{CTE}$ of the $\mathrm{Cu} / \mathrm{Gr}-\mathrm{Cu}$ composite $(\sim 5.4 \mathrm{ppm} / \mathrm{K})$ in this work is almost identical to that of silicon $(4.3 \mathrm{ppm} / \mathrm{K}),{ }^{34)}$ thus well suited for high power module devices. As a comparison, the CTE mismatch between the proposed $\mathrm{Cu} / \mathrm{Gr}-\mathrm{Cu}$ and silicon was merely $25 \%$ while $300 \%$ mismatch is found between conventional $\mathrm{Cu}$ and $\mathrm{Si}^{35,36)}$ 
(a)

$\multimap$ Exp $1 \multimap$ Exp $2 \multimap$ Standard Volume

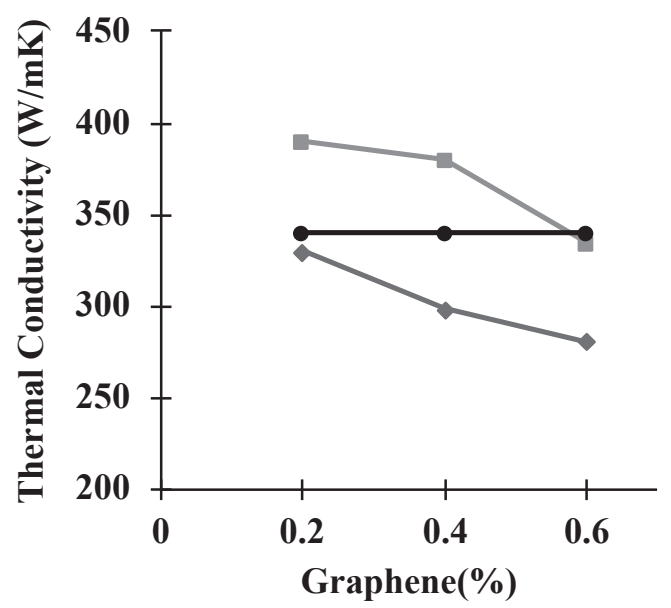

(b) $\rightarrow$ Exp1 $\because$ Exp2 $\rightarrow$ Standard Volume

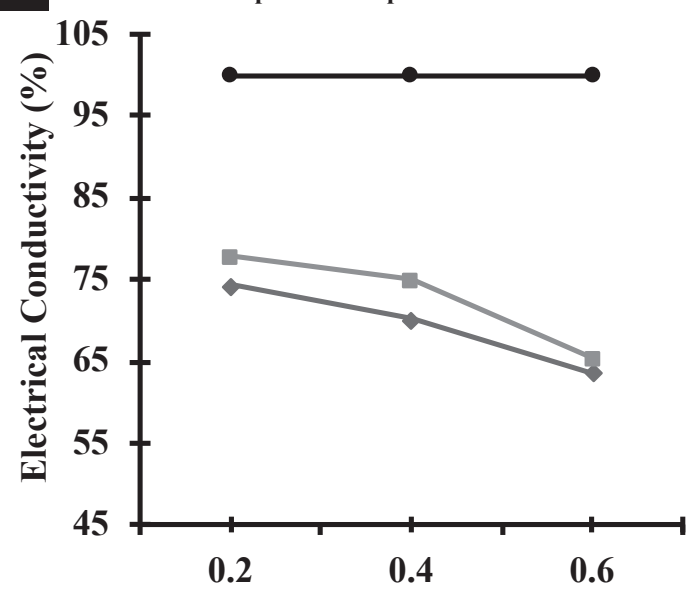

Graphene (\%)

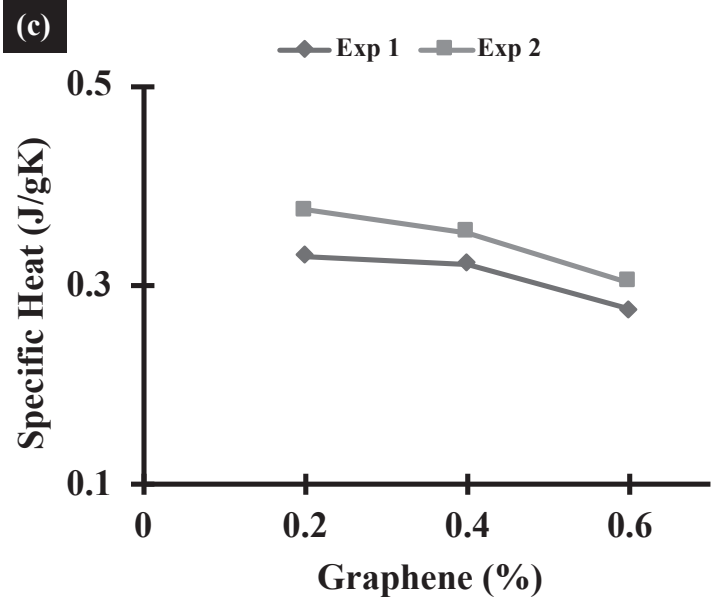

Fig. 7 (a) Copper-like thermal conductivity in $0.2 \%$ Graphene of Exp.2.

(b) Copper-like electrical conductivity in $0.2 \%$ Graphene of Exp.2.

(c) Experimental specific heat $\left(c_{p}\right)$.

In Fig. 9(a), it demonstrates the thermal conductivity Ashby plot versus CTE for the several related materials. As shown, metallic materials own high thermal conductivity and high CTE (Triangle region) whereas ceramics, dielectrics, and insulators feature lower thermal conductivity and low CTE (Rectangle region). The $\mathrm{Cu} / 0.2 \% \mathrm{Gr}-\mathrm{Cu}, \mathrm{Cu} / 0.4 \% \mathrm{Gr}-$ $\mathrm{Cu}$ and $\mathrm{Cu} / 0.6 \% \mathrm{Gr}-\mathrm{Cu}$ composites (Circular region) have

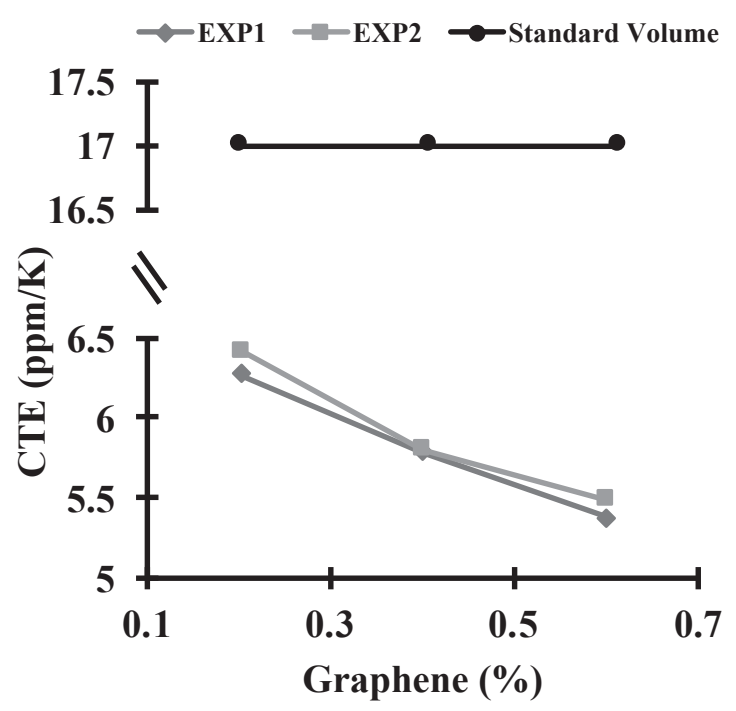

Fig. 8 The silicon-like coefficient of thermal expansion.
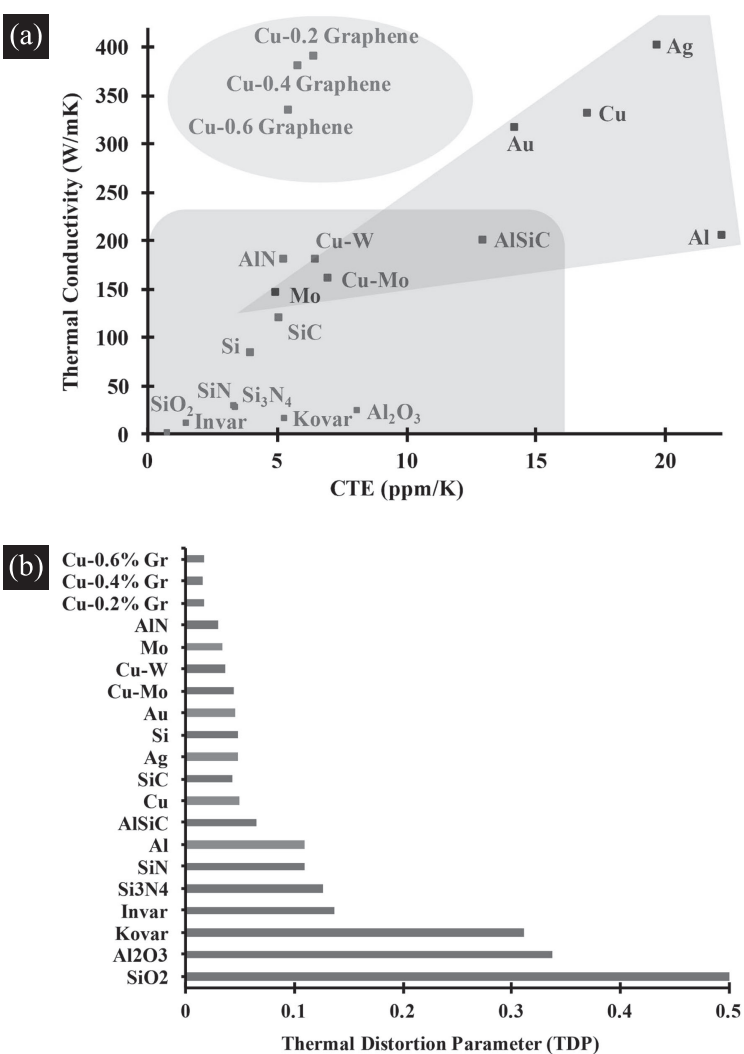

Fig. 9 (a) Ashby plot of thermal conductivity versus CTE for various IGBT materials. As it is illustrated, the $\mathrm{Cu} / \mathrm{Gr}-\mathrm{Cu}$ materials attain the best regarding high thermal conductivity and low CTE. (b) TDP comparison where the $\mathrm{Cu} / \mathrm{Gr}-\mathrm{Cu}$ represents the lowest thermal effect.

overcome this situation and dominated an exceptional place in this Ashby map with thermal conductivity as metals and coefficient of thermal expansion as silicon. Therefore, this technology will leverage both metal (high thermal conductivity) and graphene (low CTE) properties. As for CTE, the proposed composite is also matching with most of the common dielectrics and ceramics, like $\mathrm{SiO}_{2}, \mathrm{Si}$, and $\mathrm{Al}_{2} \mathrm{O}_{3}$, showing great potential for thermal management applications of high power IGBT modules. Moreover, from an engineering point of view, TDP is defined as: ${ }^{37)}$ 


$$
T D P=\frac{C T E\left(\frac{p p m}{K}\right)}{\text { Thermal Conductivity }\left(\frac{W}{m \cdot K}\right)} .
$$

TDP is one of the primary indicators in the temperatureinduced distortion of materials and widely used in metrology, optics and high-precision engineering. ${ }^{37)}$ The lower TDP indicates higher thermal stability. As for $\mathrm{Cu} / \mathrm{Gr}-\mathrm{Cu}$ composite properties, such as higher thermal conductivity and lower CTE, that can be considered as silicon replacement since its TDP is very competitive as shown in Fig. 9(b), and applicable for a wide range of applications.

\section{Conclusion}

In summary, we used metal injection molding to manufacture the uniform copper/graphene composite by using graphene and copper coated graphene. The final part demonstrated the well-mixed thermal conductivity (like copper) and coefficient of thermal expansion (like silicon) property. This composite represents an almost 95 times higher thermal conductivity against most comparative dielectrics (with lower CTE) such as Copper Tungsten $(\mathrm{Cu}-\mathrm{W})$ and an almost $68 \%$ lower coefficient of thermal expansion than copper. Therefore, the new materials $(\mathrm{Cu} / \mathrm{Gr}-$ $\mathrm{Cu}$ ) would facilitate the material selection and eliminate the current thermal conductivity and CTE issues in high power modules IGBT. Thus, we expect these materials will bring the new development window in high power modules, especially in hybrid and electric vehicles.

\section{REFERENCES}

1) Z. Khatir and S. Lefebvre: IEEE, San Jose, 2001, pp. 27-34.

2) A.M. Abyzov, S.V. Kidalov and F.M. Shakhov: Appl. Therm. Eng. 48 (2012) 72-80

3) F. Mohammadi, N. Arab and S.S. Li: Mater. Trans. 59 (2018) 12511258.

4) J. Millán, P. Godignon and A. Pérez-Tomás: Automatika Journal 53 (2012) 107-116.

5) A. Volke and M. Hornkamp, IGBT modules technologies, driver and application, Infineon.

6) C. J. Liu, G. Q. Zhang, L. J. Emst, M. Vervoort and G. Wisse, Orlando, 2001, pp. 624-631.

7) L. Deng, R.J. Young, I.A. Kinloch, R. Sun, G. Zhang, L. Noe and M. Monthioux: Appl. Phys. Lett. 104 (2014) 051907.
8) K.M.F. Shahil and A.A. Balandin: Solid State Commun. 152 (2012) 1331-1340.

9) A.A. Balandin, S. Ghosh, W. Bao, I. Calizo, D. Teweldebrhan, F. Miao and C.N. Lau: Nano Lett. 8 (2008) 902-907.

10) C.L.P. Pavithra, B.V. Sarada, K.V. Rajulapati, T.N. Rao and G. Sundararajan: Sci. Rep. 4 (2014) 4049.

11) A. Jaikumar, K.S.V. Santhanam, S.G. Kandlikar, I.B.P. Raya and P. Raghupathi: ECS Trans. 66 (2015) 55-64.

12) K. Chu, Q. Wu, C. Jia, X. Liang, J. Nie, W. Tian, G. Gai and H. Guo: Compos. Sci. Technol. 70 (2010) 298-304.

13) A. Bhat, V.K. Balla, S. Bysakh, D. Basu, S. Bose and A. Bandyopadhyay: Mater. Sci. Eng. A 528 (2011) 6727-6732.

14) Ashby Plot, Wikipedia.

15) C. Subramaniam, Y. Yasuda, S. Takeya, S. Ata, A. Nishizawa, D. Futaba, T. Yamada and K. Hata: Nanoscale 6 (2014) 2669-2674.

16) Enerage Inc., Multi Layer Graphene P-ML20, Enerage Inc., Wujie.

17) G. Ding, Y. Wang, M. Deng, X. Cui, H. Wu and L. Zhu: Carbon nanotubes - from research to applications, 2014, pp. 1-31.

18) A.M. Marconnet, M. Motoyama, M.T. Barako, Y. Gao, S. Pozder, B. Fowler, K. Ramakrishna, G. Mortland, M. Asheghi and K.E. Goodson: IEEE, San Diego, 2012, pp. 15-19.

19) A.S. Kousalya, J.A. Weibel, S.V. Garimella and T.S. Fisher: Int. J. Heat Mass Transfer 59 (2013) 372-383.

20) S. Arai and T. Osaki: J. Electrochem. Soc. 162 (2014) D68-D73.

21) P.-M. Hannula, J. Aromaa, B.P. Wilson, D. Janas, K. Koziol, O. Forsén and M. Lundström: Electrochim. Acta 232 (2017) 495-504.

22) Z. Protich, K.S.V. Santhanam, A. Jaikumar, S.G. Kandlikar and P. Wong: J. Electrochem. Soc. 163 (2016) E166-E172.

23) Hielscher, UIP16000 - ultrasonic processor.

24) T.Y. Chan, M.S. Chuang and S.T. Lin: Powder Metall. 48 (2005) 129133.

25) J.F. Sweet, M.J. Dombroski and A. Lawley: Int. J. Powder Metall. 28 (1992) 41-51.

26) K. Hayashi and T.-W. Lim: Powder Metall. 3 (1990) 129-133.

27) A. Upadhyaya and R.M. German: Int. J. Powder Metall. 32 (1998) 34-55.

28) Netzsch, LFA 447 Nano Flash, 2013.

29) Helmut-Fischer GmbH, SIGMASCOPE SIMP10.

30) Netzsch, DIL 402 PC, 2013

31) SEM SU8200, Hitachi.

32) J.L. Johnson, L.K. Tan, R. Bollina, P. Suri and R.M. German: Powder Metall. 48 (2005) 123-128.

33) D.F. Heaney: Handbook of metal injection molding, (WoodHead, 2012).

34) A.V. Mazur and M.M. Gasik: J. Mater. Process. Technol. 209 (2009) $723-727$.

35) F.S. Mark, R.B. Donald, L.-H. Duy and W. Richard: High-Density Interconnect and Systems Packaging 4217 (2000) 438-443.

36) B. Ji, X. Song, E. Sciberras, W. Cao, Y. Hu and V. Pickert: IEEE Trans. Power Electron. 30 (2015) 2493-2504.

37) I.R. Walker: Reliability in scientific research improving the dependability of measurements, calculations, equipment, and software, (Cambridge University Press, 2011) 1st edn.

38) I. T. AG: Hybrid Kit for HybridPACK 1, (Infineon Technologies AG, 2012). 